\title{
Influenza immunization practices and policies for health care students in Canada
}

\author{
Kiersten Pianosi BSc ${ }^{1,2}$, Tara Chobotuk MD ${ }^{2,3}$, Beth A Halperin RN MN $2,3,4$, Scott A Halperin MD ${ }^{2,3,5}$
}

K Pianosi, T Chobotuk, BA Halperin, SA Halperin. Influenza immunization practices and policies for health care students in Canada. Can J Infect Dis Med Microbiol 2013;24(4):195-201.

BACKGROUND: Influenza vaccine is recommended for all health care providers including health care students. Little is known about how health care student programs provide information about influenza vaccination to their students, deliver vaccines and document their vaccination status.

METHODS: A mixed-methods approach was used and included key informant interviews of program coordinators for health care student programs in Halifax (Nova Scotia) and a national survey of program coordinators of health care student programs across Canada.

RESULTS: All 21 coordinators of programs that had students placed at the IWK Health Centre (Halifax, Nova Scotia) during the influenza season were interviewed. Surveys were completed by 93 (36.3\%) of 256 eligible coordinators representing 134 different programs (response rate $52.3 \%$ ). Most programs encouraged seasonal influenza vaccination but only 28 (20.9\%) required it. None of the Halifax programs delivered influenza vaccine and most preferred a coordinated, centrally administered program. In contrast, many programs across Canada delivered influenza vaccine and did not desire a centralized process.

CONCLUSION: There is considerable variability in the delivery of influenza vaccine to health care students across Canada. Coordinated programs may be desirable where delivery programs do not already exist.

Key Words: Health care students; Immunization policy; Influenza vaccine

$\overline{\mathrm{S}^{\mathrm{e}}}$ easonal influenza is a respiratory infection caused by influenza A and B viruses that affects approximately $5 \%$ to $25 \%$ of Canadians each year (1). While most viral shedding occurs in the first two to three days after the onset of illness, the influenza virus can be transmitted by individuals who are asymptomatic or presymptomatic (2). While most patients recover, influenza results in approximately 20,000 hospitalizations and 2000 to 8000 deaths in Canada annually (1). Although annual vaccination is the primary method to decrease the occurrence and severity of influenza, only $31.7 \%$ of Canadians and $39.8 \%$ of Nova Scotians 12 years of age or older received influenza vaccinations in 2008 (3).

In the United States, $36 \%$ of health care providers $(\mathrm{HCP})$ receive the seasonal influenza vaccine annually (2). Four randomized controlled trials conducted in long-term care settings have demonstrated that vaccination of HCP is associated with substantial decreases in mortality and/or morbidity in the residents (4-7). The National Advisory Committee on Immunization recommends that all HCP and health care students (HCS) be vaccinated against influenza annually (8). In 2003, influenza vaccination rates among Canadian HCP employed in ambulatory care settings, hospitals and long-term care facilities was $46 \%$; this rate currently remains below $50 \%$ (9).

\section{Les pratiques de vaccination contre l'influenza et les politiques à l'égard des étudiants du domaine de la santé au Canada}

HISTORIQUE : L'administration du vaccin contre l'influenza est recommandée pour tous les dispensateurs de soins, y compris les étudiants du domaine de la santé. On ne sait pas grand-chose de la manière dont les programmes informent leurs étudiants du milieu de la santé du vaccin contre l'influenza, dont ils prévoient l'administration du vaccin et dont ils vérifient leur statut vaccinal.

MÉTHODOLOGIE : Les chercheurs ont privilégié une méthode mixte qui incluait des entrevues auprès d'informateurs clés, soit les coordonnateurs des étudiants des programmes du domaine de la santé de Halifax (Nouvelle-Écosse), et une étude nationale des coordonnateurs des étudiants des programmes du domaine de la santé du Canada.

RÉSULTATS : Les 21 coordonnateurs qui avaient des étudiants en stage à l'IWK Health Centre de Halifax, en Nouvelle-Écosse, pendant la saison d'influenza, ont participé à une entrevue. De plus, 93 (36,3\%) des 256 coordonnateurs admissibles ont rempli le sondage, représentant 134 programmes différents (taux de réponse de 52,3\%). La plupart des programmes favorisaient l'administration du vaccin contre l'influenza saisonnière, mais seulement 28 (20,9\%) l'exigeaient. Aucun programme de Halifax n'assurait l'administration du vaccin contre l'influenza, et la plupart auraient préféré un programme d'administration coordonné et centralisé. Par contre, de nombreux programmes au Canada administrent le vaccin contre l'influenza et ne souhaitent pas de processus centralisé.

CONCLUSION : On constate une nette variabilité dans l'administration du vaccin contre l'influenza aux étudiants du domaine de la santé du Canada. Des programmes coordonnés pourraient être souhaitables aux endroits où il n'y a pas encore de services.

At present, there are few programs in Canada and none in Nova Scotia that systematically deliver influenza immunizations to HCS, nor is there a systematic collection and sharing of information on student immunization status among institutions. Thus, there is no way to readily access this information in the case of outbreaks or unintended exposures. These shortcomings interfere with the successful and efficient delivery of HCP and HCS influenza immunization programs that are considered to be the standard of care in the protection of patients and their families. The objectives of the present study were to determine the current policies at HCS training institutions in Canada, assess the attitudes and opinions of key informants about a more coordinated influenza vaccination system, and gather the necessary information to help design a centralized and organized system for vaccine promotion/awareness, administration and data collection/tracking of influenza vaccinations for HCS.

Study setting and population

\section{METHODS}

The research protocol for the present two-phase study was approved by the Research Ethics Board at the IWK Health Centre (Halifax, Nova Scotia). The first phase consisted of interviews with key informants

\footnotetext{
${ }^{1}$ Acadia University, Wolfville; ${ }^{2}$ Canadian Center for Vaccinology, Dalhousie University and the IWK Health Centre; ${ }^{3}$ Department of Pediatrics;

${ }^{4}$ School of Nursing; ${ }^{5}$ Department of Microbiology $\mathcal{E}$ Immunology, Dalhousie University, Halifax, Nova Scotia

Correspondence: Scott A Halperin, Canadian Center for Vaccinology, Dalhousie University, IWK Health Centre,

5850/5980 University Avenue, Halifax, Nova Scotia B3K 6R8. Telephone 902-470-8141, fax 902-470-7232, e-mail scott.halperin@dal.ca
} 
TABLE 1

Key-informant-identified resources currently used

\begin{tabular}{lc}
\hline Resource & $\begin{array}{c}\text { Number of schools/programs } \\
(\mathbf{n}=\mathbf{2 1})\end{array}$ \\
\hline Program personnel to promote vaccination & $17(80)$ \\
Paper files & $4(19)$ \\
Vaccine promotion posters & $4(19)$ \\
Public Health Agency involvement & $3(14)$ \\
Websites & $3(14)$ \\
Electronic database & $2(9)$ \\
E-mails with vaccine clinic information & $2(9)$ \\
Health care students' family physicians & $2(9)$ \\
Physical space & $2(9)$ \\
Nurse & $2(9)$ \\
\hline
\end{tabular}

Data presented as $n$ (\%)

from 21 schools across 19 disciplines (Supplementary Online Table 1; go to www.pulsus.com) from July to September 2010 that had student placements during influenza season (October to May) at the IWK Health Centre (a 100-bed tertiary care pediatric and maternity/ women's hospital). Informed consent of key informants in phase I was implied by participation in an interview.

The second phase was an anonymous web-based questionnaire distributed to 256 program directors/clinical coordinators from 11 health care disciplines across Canada (Supplementary Online Table 2; go to www.pulsus.com) with the potential for clinical placements at health care institutions during the influenza season (October to May). A letter describing the research project was included as part of the national survey. Informed consent was implied by completion of the survey.

\section{Participant recruitment}

The disciplines/schools for the key informant interviews were identified by the IWK Learning and Development Office based on the list of programs that had clinical placements during the influenza season and formed the basis for the selection of the disciplines for the national survey. Appropriate personnel were identified through publicly available directories of each school/faculty and contacted directly via e-mail and/or telephone for the key informant interviews, and via e-mail for the national survey.

\section{Study design}

Key informant interviews: The key informant interviews adhered to a semistructured interview guide created by consensus of the investigators. The guide was designed with 23 short questions that served as prompts to generate discussion related to the programs' policies on influenza immunization of students, the specifics of these policies, how students are immunized, how the data regarding immunization status are collected and stored, and how these data are made available to health care institutions. The interviews occurred within a $45 \mathrm{~min}$ period at the preferred location of the key informant and were audio recorded. Notes were taken by the interviewer to record the most accurate and relevant information.

National survey: The survey instrument consisted of 20 questions concerning seven major areas: demographics; current influenza immunization policies for HCS; current methods of vaccine promotion/ education; current methods of vaccine administration; current methods of data collection and tracking influenza immunization status; benefits and drawbacks of a centrally organized system for influenza vaccination; and necessary resources to create a centrally organized system for influenza vaccination.

The questionnaire was inputted into Remark Web Survey software (Gravic Inc, USA) and uploaded to a website affiliated with the Canadian Center for Vaccinology (Halifax, Nova Scotia). The appropriate personnel from the $256 \mathrm{HCS}$ programs were informed about the study in an e-mail and were provided the URL address needed to complete the questionnaire. Potential study participants received three reminder e-mails between September and December.

\section{Statistical analysis}

Qualitative analysis was performed manually or with the aid of NVivo version 9 (QSR International, USA). Responses were categorized into groups based on common and underlying themes. The responses to the questions regarding benefits of a centrally organized system of influenza vaccine promotion, coordination of resources for a vaccine clinic, and tracking of immunization status, and the top three attributes/ components of an optimal system were combined in the qualitative analysis because of redundancy. Quantitative data analysis was conducted using SAS version 8.2 (SAS Institute, USA). For the analysis of proportions, binomial point estimates and exact binomial CIs were calculated. Two different denominators were used for the descriptive statistics based on whether the question referred to the respondent or the program (some respondents replied for multiple programs at a given institution).

\section{Key informant interviews}

\section{RESULTS}

Respondents: All 21 programs with HCS placements at the IWK Health Centre were contacted and key informants from all programs consented to participate in an interview. Programs varied in the number of HCS with placements at the IWK (range two to 226 students), with an average of 19 students per program in the 2009-2010 school year; all programs had HCS with placements during the influenza season. Immunization was the responsibility of clinical coordinators $(n=11[52 \%])$, program administrators $(n=5[24 \%])$, program directors or academic chairs $(n=2[10 \%])$, infection control practitioners $(n=1[5 \%])$ or was deferred to the IWK Health Centre's Learning and Development Office or Occupational Health and Safety Office $(n=2[10 \%])$. Nearly three-quarters $(n=15[71 \%])$ of programs had their own policy regarding HCS influenza immunization, mostly in the form of strongly encouraging their HCW students to be immunized. However, few programs had a formal written policy to support this.

Current programs: Most programs $(n=17$ [81\%]) provided information to their $\mathrm{HCS}$ on vaccine requirements and did not provide further information such as what diseases the vaccines protected against, the symptoms, severity and prevalence of these diseases, why the vaccines were required, and/or the benefits and risks of each vaccine. Three (14\%) programs provided information on the benefits of vaccination for the HCS' safety and for their patients' safety in addition to informing their HCS of vaccine requirements. One (5\%) of these programs also arranged an information session for their HCS that covered this additional vaccine information and provided information on 'frequently asked questions'. One (5\%) program covered additional vaccine information as part of the course curriculum. Programs used a variety of methods to communicate information on the vaccine policy and vaccine requirements to their $\mathrm{HCS}$, and frequently reported the use of more than one method (Table 1). Written communication (either paper copies or in an electronic format) was used in application packages, orientation manuals and course calendars. Verbal communication was used in the form of information sessions, classroom presentations and individual meetings with HCS. Visual aids, such as posters and bulletins, e-mails and website links, were also used.

Most programs ( $n=19$ [90\%]) encouraged but did not require their $\mathrm{HCS}$ to receive either the seasonal influenza and/or H1N1 vaccine(s). Two (10\%) programs did not encourage their HCS to be immunized against influenza. Of the programs that encouraged their HCS to be immunized against influenza, all reported using verbal encouragement $(n=19[100 \%])$. Some programs also used e-mails $(n=9$ [47\%]), posters $(n=7[37 \%])$, presentations $(n=2[11 \%])$, written information $(n=3[16 \%])$, individual meetings $(n=1[5 \%])$ or advocacy booths $(n=1[5 \%])$ to encourage influenza immunization.

Three-quarters $(n=16[76 \%])$ of programs either kept a paper copy of HCS vaccine documentation on file $(n=10[48 \%])$, kept both a paper copy on file and an electronic database of whether HCS vaccine documentation was complete or incomplete ( $n=4$ [19\%]), or kept only an electronic database with vaccine documentation $(n=2[10 \%])$. The 
TABLE 2

Key-informant-identified optimal characteristics of a centrally organized vaccine system

\begin{tabular}{lc}
\hline Characteristic & $\begin{array}{c}\text { Number of schools/ } \\
\text { programs (n=21) }\end{array}$ \\
\hline Convenient & $21(100)$ \\
Accurate vaccine information & $18(85)$ \\
Copy of vaccine record for HCS & $7(33)$ \\
Secure electronic database to track vaccine status & $7(33)$ \\
External personnel to track vaccine status & $5(23)$ \\
Advance notice of clinic information given to HCS & $4(19)$ \\
Vaccine educator involved & $4(19)$ \\
Additional incentives (eg, food provided, contest & $2(9)$ \\
between programs) & \\
Efficient clinic set up with short wait times & $2(9)$ \\
Specific clinic for each program & $2(9)$ \\
Student involvement & $2(9)$ \\
Other & $5(23)$ \\
\hline
\end{tabular}

Data presented as n (\%). HCS Health care students

programs that did not keep vaccine records relied on the IWK Health Centre's Learning and Development Office or the Occupational Health and Safety Office to collect the vaccine documentation on their behalf $(n=5[24 \%])$. Only four $(19 \%)$ programs had a system in place to administer influenza vaccine to their HCS. Two of these programs had HCS who were also considered employees of the IWK Health Centre and were, thus, eligible for employee influenza vaccine clinics. The other two programs had their HCS access campus influenza clinics that were campus-wide and not program-specific. All programs but one $(n=20[95 \%])$ were interested in having an influenza vaccine program administered to their HCS by someone outside of their program. The one program that was not interested had access to the IWK Health Centre employee influenza vaccine clinics.

Optimal program: Respondents cited the following benefits to having a centrally organized system of encouraging HCS to be immunized against influenza, coordinating resources for a vaccine clinic and tracking immunization status:

Logistical benefits: Respondents believed that a centrally organized system of influenza vaccine delivery would be very beneficial for HCS because it could be designed specifically to be student-friendly and better meet the students' needs (safe, accessible location, convenient time). An emphasis was placed on streamlined and efficient clinics that would cause less interruption of education. These characteristics, along with being cost free to the HCS, would provide incentives to be immunized.

Health benefits: Promoting and providing the influenza vaccine would give HCS the opportunity to obtain protection against influenza, and avoid illness and associated missed time from their educational commitments. This health benefit would also extend to their patients by decreasing influenza transmission rates. Respondents believed that a centrally organized system would provide the necessary resources for HCS to make informed choices to take responsibility for their own health.

Reliable information: Respondents were favourable toward having resources on influenza immunization from experts in the area, and believed this would provide high-quality, consistent, reliable information that would help to decrease misinformation and dispel myths. They believed it would benefit HCS to have a consistent source for obtaining information so that the HCS would not have to sort through conflicting information from a variety of external sources.

Immunization status tracking: Respondents believed that it would be beneficial to have a centrally organized system because this would provide reliable tracking of HCS immunization status. This would decrease the demand on programs to input immunization status or follow-up on missing documentation which, in turn, would boost the program's productivity. For programs or placements that require
TABLE 3

Key-informant-identified resources required for a centrally organized vaccine system

\begin{tabular}{lc}
\hline Resource & $\begin{array}{c}\text { Number of schools/ } \\
\text { programs (n=21) }\end{array}$ \\
\hline Vaccinators & $17(80)$ \\
Electronic database & $16(76)$ \\
Information to distribute to HCS & $15(71)$ \\
Posters & $8(38)$ \\
Educator/liaison & $5(23)$ \\
Physical space & $4(19)$ \\
Copy of vaccine record for HCS & $3(14)$ \\
Personnel to track vaccination status & $2(9)$ \\
Other & $2(9)$ \\
\hline
\end{tabular}

Data presented as $n$ (\%). HCS Health care students

influenza immunization, it would be easier to ensure that the vaccine has been received by HCS. In addition, respondents believed that students would appreciate having their immunization status on a tracking system in case they misplaced their personal immunization record.

Student involvement: Respondents believed that having a centrally organized system that was designed to be program-specific would send the message that influenza immunization is very important. The system may enable students to be involved as volunteers in an advocacy or planning role, thus providing a further beneficial experience. This clinic would give students the opportunity to be role models for one another. Respondents believed that word of mouth among HCS and a positive peer attitude may boost immunization rates.

Respondents cited the following as potential drawbacks to a centrally organized system for influenza immunization:

Logistical drawbacks: Respondents were concerned that there may be more demand by HCS for immunization against influenza than the available supply of the vaccine. With HCS' busy schedules, participants believed it may be difficult to find an ideal time for the vaccine clinics. If only limited clinic dates and times were offered, participants expressed concerns that some students may miss the opportunity to attend a vaccine clinic due to other commitments. Also, if the vaccine clinic was not designed optimally, respondents believed this would impair efficiency. Respondents wanted the vaccine clinic to be free from cost to students and had concerns that it may not be cost effective if the program had to cover or supplement the cost of the clinic. Finally, respondents would need to approve the centrally organized system and the information that it was providing to their HCS before such a system could be implemented, and it could be difficult to obtain approval in a timely manner.

Ethical considerations: Respondents wondered whether such a centrally organized system could exert undue pressure on HCS who are "conscientious objectors" and believed some HCS may take offense. Respondents suggested that it would need to be clear that HCS could opt out of receiving the influenza vaccine for programs in which it is not mandatory.

Immunization status tracking: Respondents place considerable importance on HCS confidentiality and want to ensure that any tracking of immunization status be performed in accordance with their confidentiality policies. Respondents believed that HCS would want to obtain their own record of their influenza immunization status after receiving the vaccine, in addition to the official tracking performed by the centrally organized system. Respondents had concerns that it may be inconvenient to obtain their HCS immunization records from the centrally organized system.

Key informants were asked to list optimal characteristics of a centrally organized vaccination system for their program (Table 2) and what resources would be needed for such a program (Table 3). All respondents cited convenience as an important feature. An optimal system would have one or more clinic dates at a time that 


\begin{tabular}{|c|c|c|}
\hline Characteristic & $\mathrm{n}(\%)$ & $\mathrm{n}(\%)$ \\
\hline Region & $93(100)$ & \\
\hline Northern & $2(2.2)$ & \\
\hline Atlantic & $13(14)$ & \\
\hline Central & $37(39.8)$ & \\
\hline Prairies & $19(20.4)$ & \\
\hline Western & $22(23.7)$ & \\
\hline $\begin{array}{l}\text { Programs responding, } \\
\mathrm{n}(\% \text { of total }) / \mathrm{n}(\% \text { of total discipline) }\end{array}$ & $134(100)$ & $256(100)$ \\
\hline Medicine & $8(6.0)$ & $13(61.5)$ \\
\hline Nursing & $43(32.1)$ & $88(48.9)$ \\
\hline Physiotherapy & $12(9.0)$ & $13(92.3)$ \\
\hline Occupational therapy & $7(5.2)$ & $13(53.8)$ \\
\hline Pharmacy & $7(5.2)$ & $9(77.8)$ \\
\hline Dentistry & $6(4.5)$ & $9(66.7)$ \\
\hline Respiratory therapy & $7(5.3)$ & $19(36.8)$ \\
\hline Nutrition and dietetics & $6(4.5)$ & $16(37.5)$ \\
\hline Child life & $4(3.0)$ & $4(100)$ \\
\hline Social work & $12(9.0)$ & $35(34.3)$ \\
\hline Paramedicine & $16(11.9)$ & $37(43.2)$ \\
\hline Other & $6(4.5)$ & \\
\hline Position & $93(100)$ & \\
\hline Program director/coordinator & $42(45.2)$ & \\
\hline Faculty/program chair & $6(6.5)$ & \\
\hline Field education coordinator & $11(11.8)$ & \\
\hline Clinical practicum coordinator & $13(14.0)$ & \\
\hline Administrator & $3(3.2)$ & \\
\hline Dean of program & $2(2.2)$ & \\
\hline Health program nurse & $6(6.5)$ & \\
\hline Other & $10(10.8)$ & \\
\hline
\end{tabular}

TABLE 5

General program information reported by phase II survey respondents

\begin{tabular}{lc}
\hline & $\mathbf{n}(\%)$ \\
\hline Clinical placements in 2010-2011 & $93(100)$ \\
$<100$ & $33(35.5)$ \\
$100-124$ & $7(7.5)$ \\
$125-149$ & $9(9.7)$ \\
$150-174$ & $3(3.2)$ \\
$175-199$ & $4(4.3)$ \\
$\geq 200$ & $37(39.8)$ \\
During influenza season & $134(100)$ \\
Yes & $127(94.8)$ \\
No & $7(5.2)$ \\
Program policy regarding student influenza immunization & $134(100)$ \\
Yes, the seasonal influenza vaccination is required & $28(20.9)$ \\
Yes, the influenza vaccine is recommended & $46(34.3)$ \\
Yes, the policy follows that of the agency/health care & $7(5.2)$ \\
institution of student placement & \\
No & $52(38.8)$ \\
Data collection on influenza immunization status & $134(100)$ \\
Yes, records in paper copy and electronic database & $29(21.6)$ \\
Yes, records in paper copy & $38(28.4)$ \\
Yes, records in electronic database & $24(17.9)$ \\
No & $43(32.1)$ \\
\hline
\end{tabular}

coordinated with the HCS schedule. Clinics should be held at a location that was convenient for the HCS, preferably at the program's site. Key informants $(\mathrm{n}=18$ [86\%]) also believed that accurate
TABLE 6

Immunization practices reported by phase II survey respondents

\begin{tabular}{lc}
\hline & $\mathbf{n}(\%)$ \\
\hline Types of information on immunizations provided to students & \\
entering program* & \\
None & $4(4.3)$ \\
List of required and/or recommended vaccines only & $25(26.9)$ \\
Benefits or reasons for vaccination & $58(62.4)$ \\
Background on required and/or recommended vaccines & $26(28.0)$ \\
Risks of receiving vaccines & $21(22.6)$ \\
Contraindications to vaccines & $17(18.3)$ \\
Program actively encourages students to obtain influenza & $134(100)$ \\
immunizations & \\
Yes & $114(85.1)$ \\
No & $20(14.9)$ \\
Influenza vaccine a requirement for entering students & $134(100)$ \\
No & $105(78.4)$ \\
Yes, the seasonal & $17(12.7)$ \\
Yes, the H1N1 vaccine & $1(0.7)$ \\
Yes, both the seasonal and H1N1 vaccine & $11(8.2)$ \\
Program in place to administer influenza vaccine to students & $134(100)$ \\
Yes & $91(67.9)$ \\
No & $43(32.1)$ \\
\hline information that applied & \\
& \\
\hline
\end{tabular}

information must be distributed to the HCS, ideally in multiple formats such as verbally and via e-mails, posters and/or other written formats. This information should provide information regarding the vaccinations, including specific benefits and risks of immunization for the HCS, and benefits for their patients and the community. Information about clinic dates and locations should be provided with sufficient advance notice.

National survey

Respondents: A total of 93 of 256 (36.3\%) eligible participants responded to the survey (Table 4). Of the 93, 13 responded on behalf of two or more HCS programs within the same institution, yielding a total of 134 individual programs and a program response rate of $52.3 \%$. Response rates according to discipline ranged from $34.3 \%$ (social work schools) to $100 \%$ (child life schools). The highest rate of response was from programs in central Canada. The highest number of responses was from nursing $(32.1 \%)$.

General information about HCS programs: Slightly more than onethird of respondents were in charge of HCS programs with $<100$ clinical placements in 2010-2011. A slightly larger number were in charge of programs with $\geq 200$ clinical placements (Table 5). Almost all $(94.8 \%)$ of the surveyed programs participated in clinical placements during the influenza season. Although 37 (39.8\%) of 93 survey respondents indicated that their student clinical placement size was $\geq 200,14(37.8 \%)$ respondents also reported not having a program policy regarding student influenza immunization. However, the majority of programs reported having some form of program policy regarding student influenza immunization (Table 5).

Immunization practices of HCS programs: A majority of survey respondents provided information on the benefits and reasons for vaccinations to students entering their program. Slightly more than onequarter $(26.9 \%)$ of respondents provided students with only a list of the required and/or recommended vaccines, and only 26 (28.0\%) programs provided entering students with background information of recommended and/or required vaccines, such as information on what disease the vaccines protected against, the symptoms, severity and prevalence of these diseases, why the vaccines were required and/or the benefits and risks of each vaccine (Table 6). Of the 134 programs, 28 (20.9\%) required entering students to receive the seasonal influenza vaccine; 




Figure 1) Top attributes/components of an optimal system for influenza vaccine delivery for health care student programs. N/A Not applicable

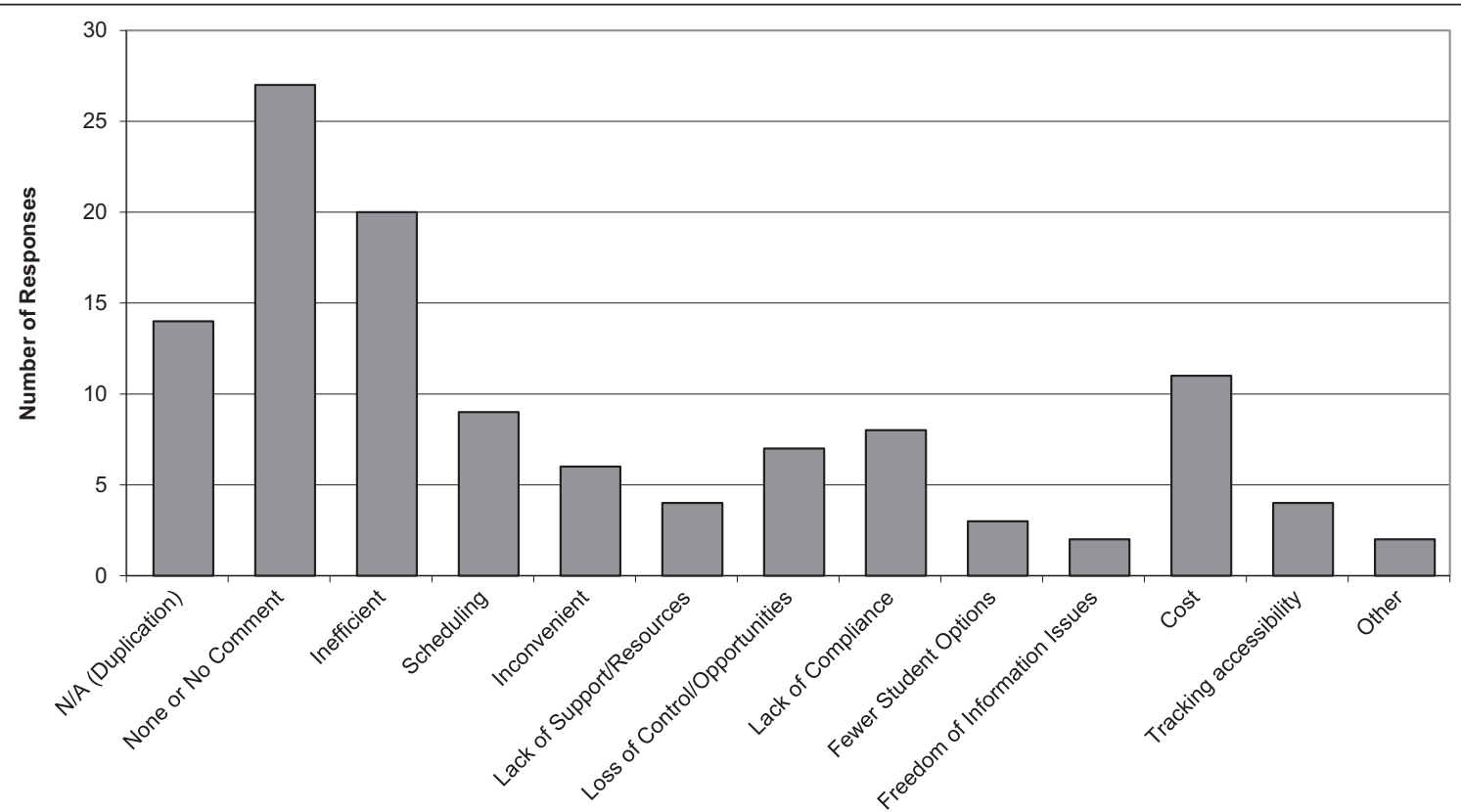

Potential Drawback

Figure 2) Potential drawbacks of a centrally organized system of influenza vaccine promotion, coordination of resources for a vaccine clinic, and tracking of immunization status. N/A Not applicable

23 of these 28 programs (82.1\%) are located in British Columbia or Ontario. Despite only 28 programs reporting the influenza vaccine as a requirement for entering students, $91(67.9 \%)$ have a program in place to administer the vaccine to students (Table 6).

Future influenza immunization practices: Only 39 programs $(29.1 \%)$ indicated interest in having an influenza vaccine program administered to their students by someone outside of the program. Of those, 26 already had a program in place to administer influenza vaccine to students.

There were 196 attributes/components suggested for an optimal system for influenza vaccine delivery for HCS programs. The responses were categorized into 19 themes. Forty $(43 \%)$ respondents answered with 'no comment', 'none' or 'not applicable', 13 of whom reported having a vaccine program in place (Figure 1). Of the 53 remaining respondents, the most important attributes were easy access (33 respondents), followed by cost efficiency (20 respondents). A similar question regarding the benefits of a centrally organized system of influenza vaccine promotion, coordination of resources for a vaccine clinic and tracking of immunization status garnered identical responses from $51(54.8 \%)$ of the respondents. The most frequent themes from the remaining 42 respondents were less work (for the coordinator), central record-keeping and sharing of information, and easier/more likely student vaccinations.

The survey respondents provided 117 responses related to the drawbacks of such a centrally organized system (Figure 2). Fourteen 
responses from 93 respondents were not applicable due to duplication, and 27 responses were 'none' or 'no comments'. From the 52 remaining respondents, 20 stated inefficiency as a potential drawback and 11 stated cost. Other notable responses for potential drawbacks were scheduling (nine responses), lack of compliance (eight responses) and loss of control/opportunities (seven responses).

\section{DISCUSSION}

Influenza can be a life-threatening illness in individuals with preexisting illness such as hospitalized patients (8). Provision of influenza vaccine to HCPs is a standard of care in North America and is used as a hospital accreditation quality assurance outcome in the United States $(8,10)$. Many hospitals throughout Canada have interinstitutional agreements with provincial health agencies and schools to enable HCS to have clinical placements at these hospitals. These students have a risk that is similar to HCPs for transmitting the influenza virus to patients. We found few programs in Canada that systematically deliver influenza information and vaccine to these students; therefore, there is an opportunity to develop a coordinated system for vaccine promotion/awareness, administration and data collection/tracking.

The benefits of influenza vaccination of HCP in hospitals and long-term care facilities have been well documented (6-9). Furthermore, a 2006 study investigated the effects of a comprehensive influenza vaccination campaign for HCP in a pediatric cancer hospital. Similar to our proposed influenza vaccination program for HCS, the campaign was a three-component approach including education (about the benefits of vaccinations), increased vaccine availability and individual follow-up/feedback. Implementing this campaign before the 2004-2005 influenza season resulted in an increase in HCP vaccination rate from $44.7 \%$ to $80 \%$ (11). In studies assessing the attitudes and beliefs of HCP about influenza vaccine, fear of side effects, perceived low risk of contracting influenza, lack of time/forgetting, and violation of freedom of choice were some of the highest ranking reasons for not receiving the influenza vaccine $(12,13)$. Although the opinions and attitudes of HCP about influenza vaccination have been studied and assessed, there has been no study investigating influenza vaccination programs among HCS, and whether their attitudes and opinions differ from those of HCP. However, we speculate that HCS and HCP may have similar opinions and attitudes, given that they work in similar settings and work cultures.

Ease, convenience, lighter workload and increased rate of vaccination were attributes of an ideal program that appeared frequently in key informant and survey respondents across Canada. Flexible scheduling was also indicated as one of the top three attributes of an optimal system for influenza vaccine delivery for HCS programs. These findings imply that for such a program to be successful, it must be of minimal burden, in terms of time and work, for the HCS programs involved. In addition, the influenza vaccine program would have to be designed around the schedules of the HCS programs.

The results of the present study demonstrate that distribution of information on immunizations (education) to HCS is variable and lacking in many programs. More than one-quarter (26.9\%) of national survey respondents indicated that only a list of recommended and/or required vaccines is distributed to students entering their program. Although most programs have a policy regarding HCS influenza immunization, less than one-third required influenza vaccination, with $>75 \%$ of those programs located in Ontario or British Columbia.

Substantial differences were found between the key informant interviews in Halifax and the national survey responses regarding a desire to have a coordinated influenza vaccine delivery program. Most Halifax programs encouraged influenza vaccination and kept immunization records but did not deliver the vaccine. In contrast, $67.9 \%$ of programs surveyed had an influenza vaccination program in place. Nearly all of the Halifax programs favoured a coordinated vaccination program, whereas only $29.1 \%$ of respondents to the national survey indicated that their program would be interested in having an influenza program administered to students on their behalf by someone outside of the program. The difference in the responses may reflect the current lack of coordination of delivery of influenza vaccine in the Halifax area. A limitation of the study design may explain, in part, the differences in the interview and survey results. With key informants, potential misinterpretations of the question could be resolved during the structured interview. The question on both the semiconstructed interview guide and the online survey read: "Would your program be interested in having an influenza vaccine program administered to students (on your behalf) by someone outside of the program?" It is possible that the use of the word 'administered' in the question may have led some survey respondents to assume the program was only for influenza vaccine delivery, when in reality it was intended to refer to a three-part program for influenza vaccine promotion/awareness, administration and data collection/tracking of immunization status for HCS.

Another potential limitation of the present study is that we surveyed program coordinators for health care student programs and did not survey HCS directly. It is possible that the program coordinators' perpectives and opinions differ from those of HCS and that their values are different. In addition, we did not attempt to evaluate the cost effectiveness of such a coordinated program, which would factor into feasibility. Furthermore, our study did not purport to determine coverage rates for influenza vaccination year-by-year at the programs surveyed. Nor did we determine whether vaccination rates were indeed higher in programs with coordinated programs for vaccine delivery, as we surmise. These would be important areas for future studies to address.

Results from the present study indicate that although many HCS programs across Canada have a standard method of vaccinating their students against influenza, none have a coordinated system for influenza vaccine promotion/awareness, administration and data collection/tracking of immunization status. The indicated lack of coordination surrounding HCS influenza vaccination could be improved by more collaboration among HCS programs and health care institutions. While there is no consensus of what would comprise the 'ideal' program, a number of factors identified in the present study should be considered including provision of information, accessibility, record keeping and follow-up. Accurate and reliable information should be provided for students in multiple formats (eg, posters, printed material, e-mail, web-based, smartphone compatible) and should include information on influenza and the risks and benefits of vaccination for both the student and his/her patients. The influenza vaccine program should also be promoted through multiple media (eg, posters, printed material, e-mail, text messaging) with advance notice of clinic dates and times, and multiple reminders. As with HCP, clinics for HCS should be conveniently located at times when the students gather for other reasons (eg, between classes, in student lounges). As appropriate, student involvement in vaccination should be facilitated to encourage ownership of the program. Feedback from HCS about the program should be encouraged and the program modified based on these suggestions. Secure, retrievable electronic tracking of HCS who were vaccinated (and those who were not) is essential and these data need to be provided to the health care institutions where the students have placements during the influenza season. Counselling for those who refuse vaccination should be available to identify reasons for refusal and to facilitate methods to address these concerns. Although these general principles underlie any optimal HCS vaccination program, the local situation should be assessed in each location and a method to ensure provision of vaccination information, convenient delivery of vaccination and record keeping with shared access to the information should be established. Evaluation of the implemented systems is essential through measurement of vaccine coverage among HCS and HCP.

ACKNOWLEDGEMENTS: The authors thank Dr Joanne Langley, Dr Janice Graham, and Dr Shelly McNeil for discussions about the design of the study and analysis, Donna MacKinnon-Cameron for assistance with data management and statistical analysis, and Diana Janowitz for assistance with qualitative data analysis. This study was supported by a Category A grant from the IWK Health Centre. 


\section{REFERENCES}

1. National Advisory Committee on Immunization. Canadian Immunization Guide. Seventh Edition. Ottawa: Canadian Medical Association, 2006

2. Lau LL, Cowling BJ, Fang VJ, et al. Viral shedding and clinical illness in naturally acquired influenza virus infections. J Infect Dis 2010;201:1509-16.

3. Statistics Canada. Influenza immunization: Fact sheet on influenza immunization. <www.statcan.gc.ca/pub/82-625-x/2010001/ article/11105-eng.htm $>$ (Accessed February 8, 2010).

4. Potter J, Stott DJ, Roberts MA, et al. Influenza vaccination of health care workers in long-term-care hospitals reduces the mortality of elderly patients. J Infect Dis 1997;175:1-6.

5. Carman WF, Elder AG, Wallace LA, et al. Effects of influenza vaccination of health-care workers on mortality of elderly people in long-term care: A randomized controlled trial. Lancet 2000;355:93-7.

6. Hayward AC, Harling R, Wetten S, et al. Effectiveness of an influenza vaccine programme for care home staff to prevent death, morbidity, and health service use among residents: Cluster randomised controlled trial. BMJ 2006;333:1241.
7. Lemaitre M, Meret T, Rothan-Tondeur M, et al. Effect of influenza vaccination of nursing home staff on mortality of residents: A cluster-randomized trial. J Am Geriatr Soc 2009;57:1580-6.

8. National Advisory Committee on Immunization. Statement on seasonal trivalent inactivated influenza vaccine (TIV) for 2010-2011. Can Commun Dis Rep 2010;36(ACS-6):1-49.

9. Lam P, Chambers LW, Pierrynowski-MacDougall DM, McCarthy AE. Seasonal influenza vaccination campaigns for health care personnel: Systematic review. CMAJ 2010;182:542-8.

10. Centers for Disease Control and Prevention. Key facts about influenza (flu) and flu vaccine. <www.cdc.gov/flu/keyfacts.htm> (Accessed June 13, 2010).

11. McCullers JA, Speck KM, Williams BF, Liang H, Mirror J Jr. Increased influenza vaccination of healthcare workers at a pediatric cancer hospital: Results of a comprehensive influenza vaccination campaign. Infect Control Hosp Epidemiol 2006;27:77-9.

12. Hakim H, Gaur AH, McCullers JA. Motivating factors for high rates of influenza vaccination among healthcare workers. Vaccine 2011;29:5963-9.

13. Abramson $\mathrm{ZH}$, Levi $\mathrm{O}$. Influenza vaccination among primary healthcare workers. Vaccine 2008;26:2482-9. 


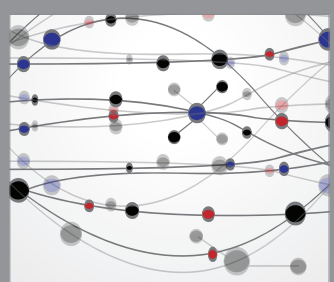

The Scientific World Journal
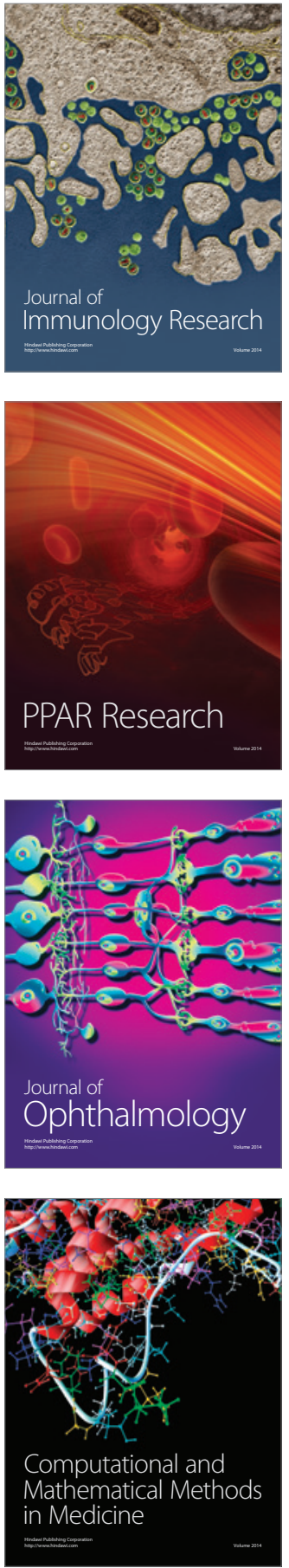

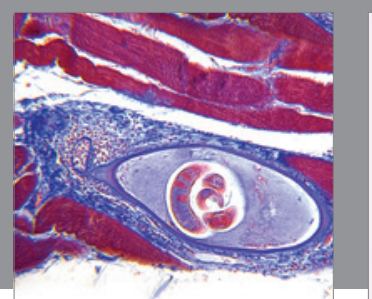

Gastroenterology Research and Practice

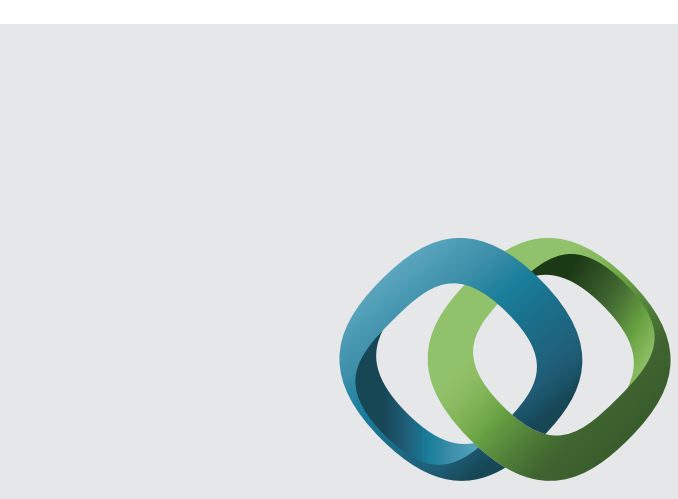

\section{Hindawi}

Submit your manuscripts at

http://www.hindawi.com
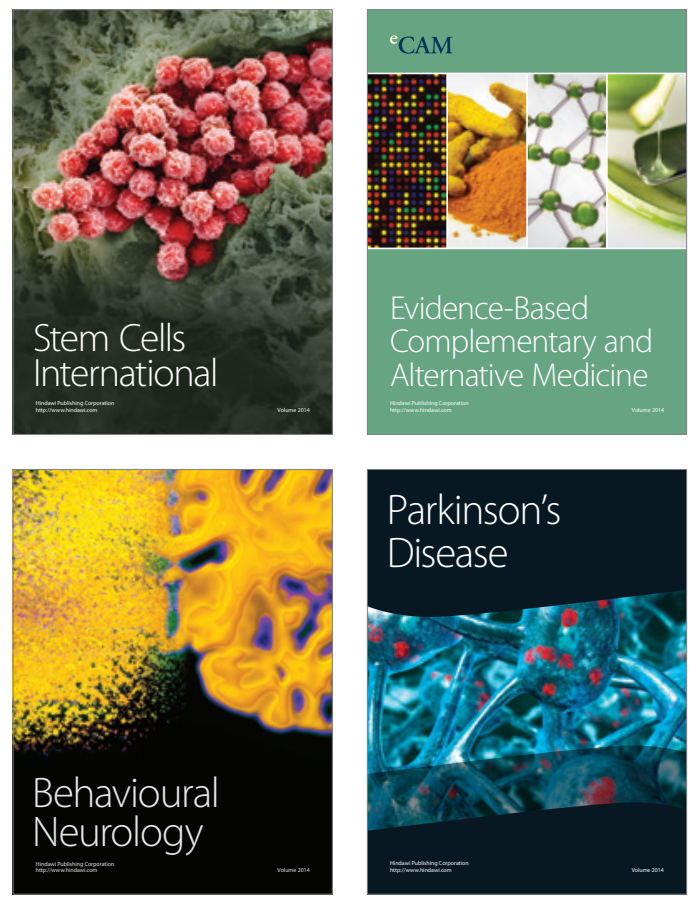
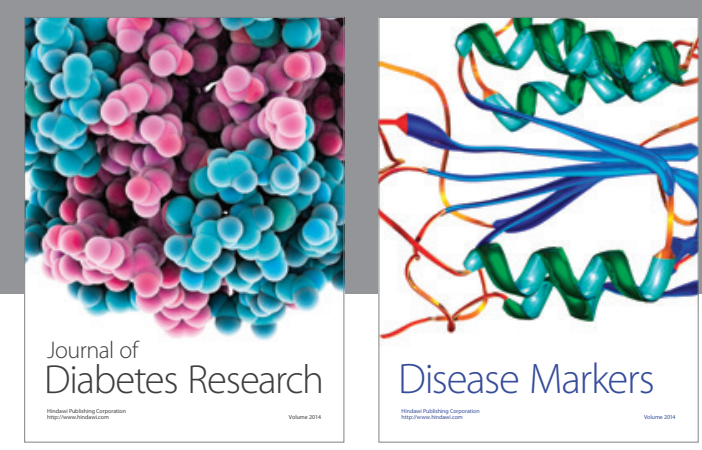

Disease Markers
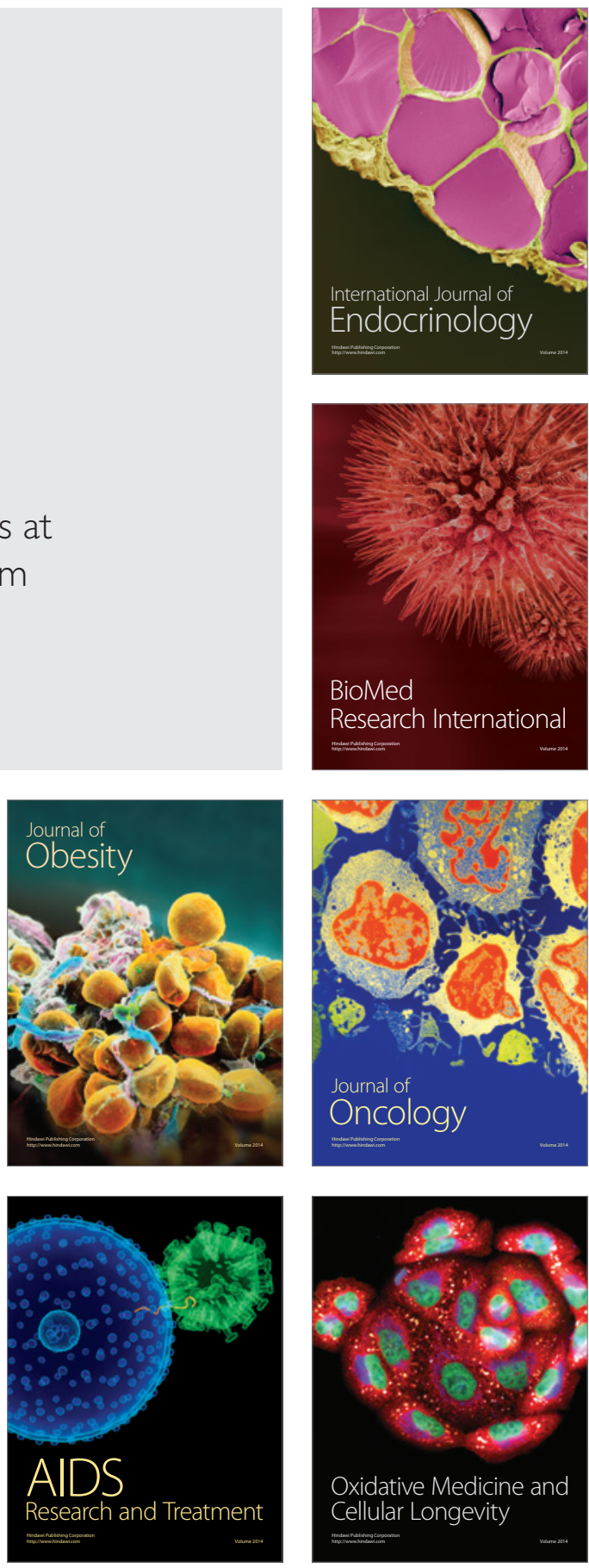